\title{
The Applications of Advanced Technologies in Dispelling Students Doubts' about Their Majors
}

\author{
Xinxue Wang, Yingying Pu*, Lei Guan, Huifang Li, Shidie Wang, Chongyang Liu, Zhaorong Shi, Dengguang Yu \\ School of Materials Science \& Engineering \\ University of Shanghai for Science \& Technology \\ Shanghai 200093, China \\ E-mail addresses: puyingying@usst.edu.cn
}

\begin{abstract}
In China, many college students don't know their majors well during choosing them after their successful college entrance examinations. When they go into the college and begin their specialty learning, they are often puzzled by a series of doubts about their discipline knowledge. How to help them to dispel those doubts is very important for them to become senior professional talents in the future. In this paper, an approach is put forward as an alternative method for eliminating the college students' learning doubts about their major. Based on two advanced technologies (electrospinning and electrospraying), some positive teaching materials are refined to dispel the students' doubts and meanwhile increasing their interests about the professional knowledge for those majoring in the specialty of Material Science and Engineering. The strategies exhibited here should be similarly useful for college students majoring in other disciplines.
\end{abstract}

Keywords_professional knowledge; learning doubts; advanced technology; undergraduate students

\section{Three REALMS OF PROFEsSiONAL KNOWLEDGE LEARNING}

Qingyuan Xingsi (Jingju monk), a master of Zen in Song Dynasty, put forward the three realms of Zen meditation: the first realm is "To see mountain is mountain, to see water is water"; the second realm is To see mountain is not mountain, to see water is not water"; and the third realm is "To see mountain is still the mountain, to see water is still the water". These three realms reflect the three realms of life, and the study of professional knowledge.

The first realm in professional learning "to see mountains is mountains, to see water is water" for the college students means that they know only the most common knowledge about their major. This is the beginning of their impressions on their discipline, but also with curiosity and freshness of the professional knowledge, to see every piece of knowledge with a simple and straightforward perspective. Mountains are mountains, water is water. They see professional things with a focus on the physical phenomena, without thinking deeply, so they believe that things are what they see. However, if their understanding of the professional knowledge stays on the surface, they can't see through the mystery of their major. Eventually, they will encounter a wall everywhere in reality of professional career, thus doubting the reality and usefulness of their discipline knowledge.
The second realm in professional learning "to see mountains is not mountains, to see water is not water" means that the students hold a negative attitude to the learning knowledge, reflecting there are many kinds of doubts about their studies on discipline. This is because that too many truths and rules are hidden behind the false mask -- the general cognition on their major, and what they see is not necessarily true. Looking at flowers in fog is like fantasy, without the capability of distinguishing the true or false. Mountains are not mountains; water is not water. Under this situation, it's easy for them to lose their direction in pursuing professional knowledge, following by confusion, hesitation, pain and struggle. Falling into a lost world, they begin to treat their majors and studies without their hearts. Mountain is no longer a mountain in pure meaning, nor is water in pure meaning. Their discipline knowledge is no longer their goals pursued wholeheartedly.

\section{The Main Doubts ABout the Professional KNOWLEDGE}

At the first stage, the college students know about their discipline in a general manner. They know that this discipline is useful for the society, and that to learn well about the knowledge needs to study hard. This stage is mainly associated with the students majoring in this discipline in their first college life. They have few puzzles in this time period. Just as they stand at the foot of a high mountain (Fig. 1)

At the third stage, the college students gradually know the whole situation about their discipline after several years' hard studying. They know that the professional knowledge can be an important support for them to make a living in the real society. Similarly, they have few puzzles in this time period because they go into a stage that the professional knowledge will be exploited to create wealth for the society. Just as they have reached an enough height during the mountain climbing process to have a relative full overlook on their major.

Most possibly, the main puzzles of the college students during their study processes concentrate in the second step, i.e. the hard process of climbing the mountain, the hard study about the professional knowledge. At this time period, the typical doubts can be categorized as follows:

How much professional knowledge or lessons that they must study? 
How to study deeply on their major based on a suitable curriculum?

What is the main usage of the studied professional knowledge?

How can I find a job in the society based on the grasped knowledge?

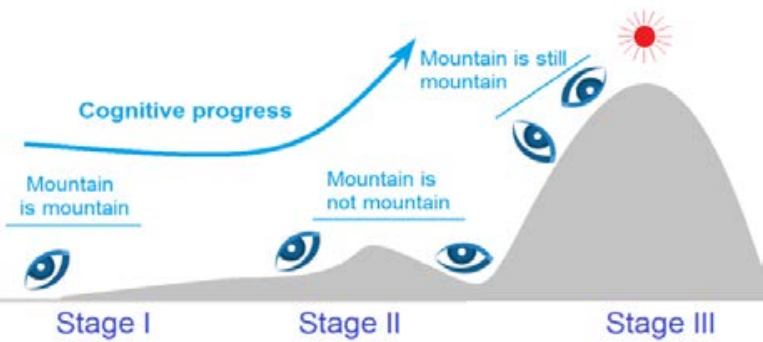

Fig. 1. The cognitive process of college students on their major.

\section{The Applications of Advanced TeCHNiques in DisPELLING DOUBTS ABOUT PROFESSIONAL KNOWLEDGE LEARNING}

\section{A. The applications of electrospinning in dispelling doubts about professional knowledge learning}

The advanced techniques in each discipline represent the most useful methods that can be utilized to benefit society. The systematic and complete grasps of these techniques need a long time period to study, to practice in their major and the related fields. It is impossible for the freshmen and sophomores. However, the simple showing process of these advanced techniques can greatly broaden their ken, increase their study interests, and point out a clear direction for their professional studies, eliminating their doubts naturally. Thus, in the present job, two electrohydrodynamic atomization (EHDA) techniques in Materials Science and Engineering are exhibited to show a way for clearing up uncertainties.

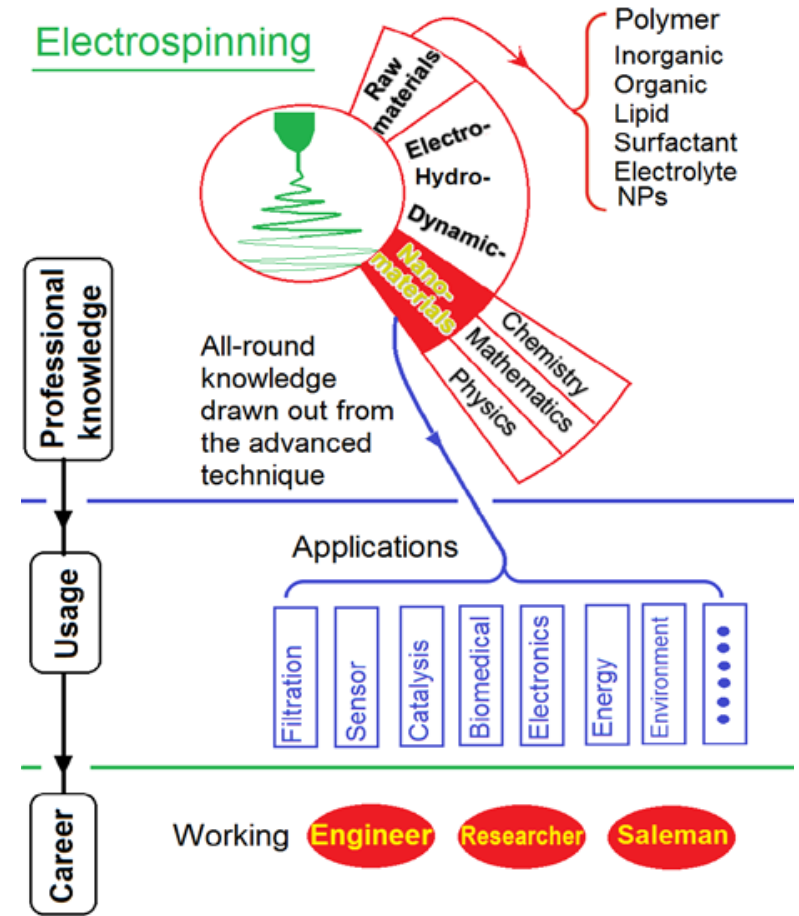

Fig. 2. Electrospinning, advanced nanotechnology for creating nanofibers, can be useful tools for dispelling a series of doubts of the students majoring in materials science and engineering.

The first one is electrospinning, or electrostatic spinning, which is a straightforward process for generating nanofibers through a single-step "top-down” manner [1-7]. Corresponding to dispel the above-mentioned several doubts, the following benefits can be achieved for the junior college students majoring in Material Science and Engineering.

Shown in Fig. 2, electrospinning can be useful tools for dispelling a series of doubts of the students majoring in Materials Science and Engineering. First of all, the students should know that the professional knowledge about raw materials (polymer, organic/inorganic materials, lipid, surfactants, electrolytes, and other types of nanoparticles (NPs) about the technologies for creating advanced materials, and about some fundamental courses (mathematics, physics and chemistry) should be studied during the college life. These materials are frequently utilized as the raw materials in the electrospinning processes [8-11], particularly modified coaxial and tri-axial electrospinning due to their capability of treating un-spinnable fluids [12-14].

Secondly, the curriculums have been designed by their teachers based on many years' experiences, which should be systematic and should keep pace with times. What is most important is that college students should deepen their professional cognitions through more scientific experiments and practice training. Electrospinning can give a series of opportunities for a wide variety of practice training, such as preparing working fluids, carrying out the working processes, trying the application in real life of the electrospun nanoproducts. 
Third, the knowledge of electrospinning can be expanded to almost all other types of material treatment knowledge. Particularly, the usage of electrospun nanofibers can be found in almost all over the applied fields such as filtration, sensor, catalysis, biomedical, electronics, energy, and environments (Fig. 2). Due to the smaller diameter, high surface area, huge porosity and the typical 3-D web inner structure nanofibers have shown the great potential application in drug delivery [1518].

Fourthly and the most important issue, with the grasp of knowledge about material science and engineering and the abundant practice experiences that can be strengthened through electrospinning, the college students should have the advantages of finding a suitable job for exerting both their knowledge and their capability. Engineers, researchers, and salesmen are all possible for them based on their enthusiasms.

\section{B. The applications of electrospraying in dispelling doubts about professional knowledge learning}

Similarly, as a peer advanced technology of electrospinning, electrospraying can be useful for teaching materials to dispel learning doubts for the college students majoring in Material Science and Engineering. Electrospraying, a straightforward process for generating micro-/nano- particles in a single-step manner, is also a "top-down" nanofabrication technology that takes advantage of the interactions between the working fluids and the high voltage electrostatic energy [19-22].

Shown in Fig. 3, electrospraying, just as electrospinning, can be explored to eliminate a series of puzzles of the students majoring in Materials Science and Engineering. The students should know that the professional knowledge about the starting materials, about the mechanism of working processes, and about some fundamental knowledge. The crude materials such as lipid and polymers are frequently utilized to prepare working fluids for the electrospraying processes $[23,24]$.

The curriculums designed by the teachers can keep pace with the most recent development in the related fields. The college students can broaden and deepen their professional knowledge through experiments and practice training with electrospraying as a main topic. The knowledge of electrospraying can be extended to other types of material treatment knowledge. Particularly, the usage of electrosprayed nanoparticles can be found in all the applied fields [25-27]. The grasp of knowledge about electrospraying and the related practice experiences can help the college students to find suitable jobs for exerting both their knowledge and their capability.

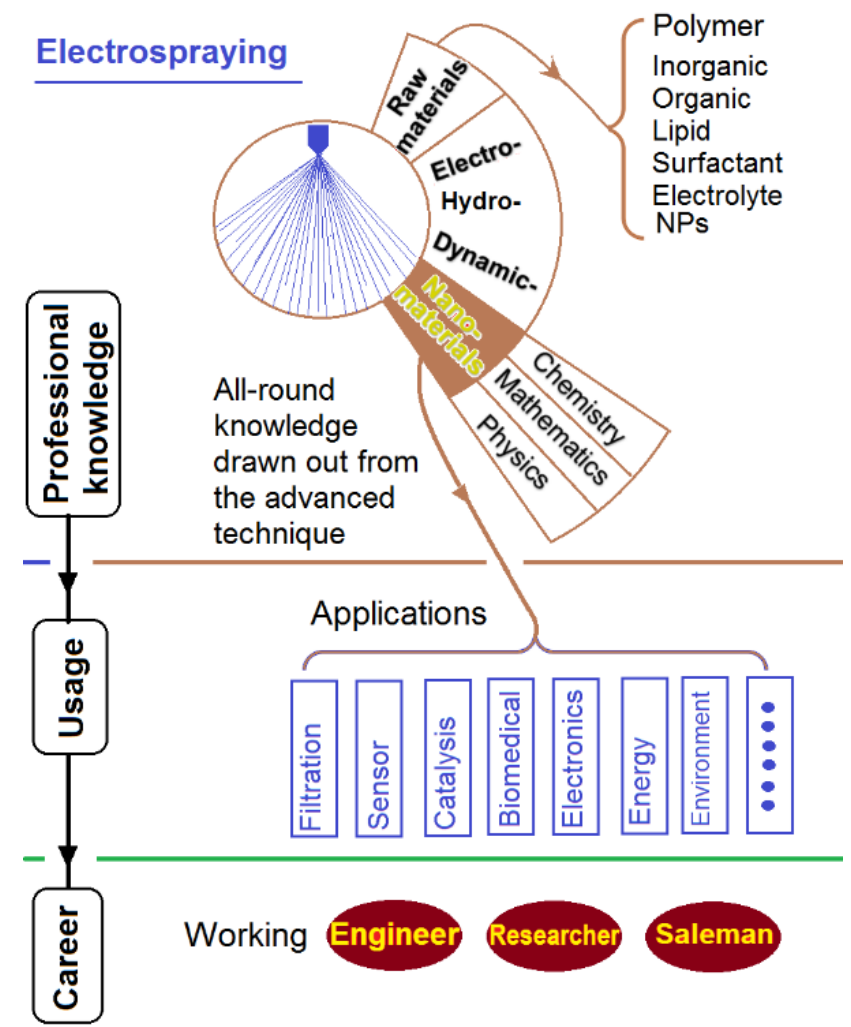

Fig. 3. Electrospraying, advanced technology for creating micro-/nanoparticles, can be useful tools for dispelling a series of doubts of the students majoring in materials science and engineering.

\section{SUMMARY}

In the present paper, the doubts of college students on their discipline knowledge learning are concluded. Effectively eliminating these doubts would greatly promote their interests in their studies and foster them into talents in the future. With two advanced technologies frequently utilized in Materials Science and Engineering (electrospinning and electrospraying) as models, some protocols are put forward here for dispelling the college students' learning doubts about their major. These doubts include the contents of their professional knowledge, their curriculums about the discipline, the potential usage of their professional knowledge, and the supports gained from the professional knowledge for making a living in the society in future. Both electrospinning and electrospraying can provide vivid teaching materials for dispelling these doubts, elevating the college students' confidences in professional knowledge learning. The strategies exhibited here can be similarly useful for college students majoring in other disciplines.

\section{ACKNOWLEDGMENT}

The financial supports are from the Shanghai Education Science Research Project (C17058) and USST college student innovation projects (SH2019217 \& 2019222/230) are appreciated. 


\section{REFERENCES}

[1] D.G. Yu, J.J. Li, M. Zhang, and G.R. Williams, "High-quality Janus nanofibers prepared using three-fluid electrospinning," Chem. Commun., vol.53, pp.4542-4545, 2017.

[2] H.F. Wen, C. Yang, D.G. Yu, X.Y. Li, D.F. Zhang, "Electrospun zein nanoribbons for treatment of lead-contained wastewater,” Chem. Eng. J., vol.290, pp.263-272, 2016.

[3] Y. Xu, J.J. Li, D.G. Yu, G.R. Williams, J.H. Yang, and X. Wang, "Influence of the drug distribution in electrospun gliadin fibers on drugrelease behavior,” Eur. J. Pharm. Sci., vol.106, pp.422-430, 2017.

[4] K. Wang, X.K. Liu, X.H. Chen, D.G. Yu, Y.Y. Yang, and P. Liu, "Electrospun hydrophilic Janus nanocomposites for the rapid onset of therapeutic action of helicid," ACS Appl. Mater. Interfaces, vol.10, pp.2859-2867, 2018.

[5] Y.H. Wu, D.G. Yu, H.P. Li, X.Y. Wu, and X.Y. Li, "Medicated structural PVP/PEG composites fabricated using coaxial electrospinning," e-Polymers, vol.17, pp.39-44, 2017.

[6] X. Liu, W. Shao, M. Luo, J. Bian, D.G. Yu, "Electrospun blank nanocoating for improved sustained release profiles from medicated gliadin nanofibers,” Nanomaterials, vol.8, no.184, 2018.

[7] D.G. Yu, J.J. Li, G.R. Williams, and M. Zhao, "Electrospun amorphous solid dispersions of poorly water-soluble drugs: A review,” J. Control. Release, vol. 292, pp.91-110, 2018.

[8] T. Hai, X. Wan, D.G. Yu, K. Wang, Y. Yang, Z.P. Liu, “Electrospun lipid-coated medicated nanocomposites for an improved drug sustainedrelease profile,” Mater. Design, vol.162, pp.70-79, 2019.

[9] Q. Wang, D.G. Yu, L.L. Zhang, X.K. Liu, Y.C. Deng, and M. Zhao, "Electrospun hypromellose-based hydrophilic composites for rapid dissolution of the poorly water-soluble drug," Carbohydr. Polym. vol.174, pp.617-625, 2017.

[10] Y.Y. Yang, Z.P. Liu, D.G. Yu, K. Wang, P. Liu, X. Chen, "Colonspecific pulsatile drug release provided by electrospun shellac nanocoating on hydrophilic amorphous composites,” Int. J. Nanomed., vol.2018, pp. 2395-2404, 2018.

[11] J.J. Li, Y.Y. Yang, D.G. Yu, Q. Du, X.L. Yang, "Fast dissolving drug delivery membrane based on the ultra-thin shell of electrospun core-shell nanofibers,” Eur. J. Pharm. Sci., vol.107, pp.195-204, 2018.

[12] H. Zhou, Z. Shi, X. Wan, H. Fang, D.-G. Yu, X. Chen, P. Liu, "The relationships between process parameters and polymeric nanofibers fabricated using a modified coaxial electrospinning," Nanomaterials, vol.9, no.843, 2019

[13] Y. Yang, W. Li, D.G. Yu, G. Wang, G.R. Williams, Z. Zhang, “Tunable drug release from nanofibers coated with blank cellulose acetate layers fabricated using triaxial electrospinning,” Carbohydr. Polym., vol.203, pp.228-237, 2019

[14] Y. Yang, W. Li, D.G. Yu, G. Wang, G.R. Williams, Z. Zhang, "Tunable drug release from nanofibers coated with blank cellulose acetate layers fabricated using tri-axial electrospinning,” Carbohydr. Polym., vol.203, pp.228-237, 2019

[15] X. Liu, Y. Yang, D.G. Yu, M.J. Zhu, M. Zhao, G.R. Williams, “Tunable zero-order drug delivery systems created by modified triaxial electrospinning,” Chem. Eng. J., vol. 356, pp.886-694, 2019.

[16] W. Huang, Y. Yang, B. Zhao, G. Liang, S. Liu, X.-L. Liu, and D.G. Yu, "Fast dissolving of ferulic acid via electrospun ternary amorphous composites produced by a coaxial process," Pharmaceutics, vol.10, no.115, 2018

[17] Z. Zhang, W. Li, G. Wang, Y.L. Qu, and D.G. Yu, "Electrospun 4th generation solid dispersions of poorly water-soluble drug utilizing two different processes,” J. Nanomater. vol.2018, no.2012140, 2018.

[18] Q. Wang, D.G. Yu, S.Y. Zhou, C. Li, and M. Zhao, "Fabrication of amorphous electrospun medicated-nanocomposites using a Teflon-based concentric spinneret,” e-Polymer, vol.18, pp.3-11, 2018.

[19] Z.P. Liu, Y.Y. Zhang, D.G. Yu, D. Wu, and H.L. Li, "Fabrication of sustained-release zein nanoparticles via modified coaxial electrospraying,” Chem. Eng. J., vol.334, pp.807-816, 2018.

[20] X.Y. Li, Z.B. Zheng, D.G. Yu, X.K. Liu, Y.L. Qu, and H.L. Li, "Electrosprayed sperical ethylcellulose nanoparticles for an improved sustained-release profile of anticancer drug," Cellulose, vol.24, pp.55515564, 2017

[21] D.G. Yu, X. L. Zheng, Y. Yang, X. Y. Li, G.R. Williams, M. Zhao, "Immediate release of helicid from nanoparticles produced by modified coaxial electrospraying,” Appl. Surf. Sci., vol.473, pp.148-155, 2019.

[22] Y.Y. Yang, M. Zhang, K. Wang, and D.G. Yu, “pH-sensitive polymer nanocoating on hydrophilic composites fabricated using modified coaxial electrospraying,” Mater. Lett., vol.227, pp.93-96, 2018

[23] Y.Y. Yang, M. Zhang, Z.P. Liu, K. Wang, and D.G. Yu, "Meletin sustained-release gliadin nanoparticles prepared via solvent surface modification on blending electrospraying," App. Surf. Sci., vol.434, pp.1040-1047, 2018.

[24] K. Wang, H.F. Wen, D.G. Yu, Y. Yang, and D.F. Zhang, "Electrosprayed hydrophilic nanocomposites coated with shellac for colon-specific delayed drug delivery,” Mater. Design, vol.143, pp.248255, 2018.

[25] Z.P. Liu, L.L. Zhang, Y.Y. Yang, D. Wu, G. Jiang, and D.G. Yu, "Preparing composite nanoparticles for immediate drug release by modifying electrohydrodynamic interfaces during electrospraying," Powder Technol., vol.327, pp.179-187, 2018.

[26] W. Huang, Y. Hou, X. Lu, Z. Gong, Y. Yang, X.-J. Lu, X.-L. Liu, D.G. $\mathrm{Yu}$, "The process-property-performance relationship of medicated nanoparticles prepared by modified coaxial electrospraying,' Pharmaceutics, vol.11, no.226, 2019.

[27] J.A. Tapia-Hernández, C.L. Del-Toro-Sánchez, F.J. Cinco-Moroyoqui, S Ruiz-Cruz, J. Juárez, D.D. Castro-Enríquez, ET AL. Gallic acid-loaded zein nanoparticles by electrospraying process. J. Food Sci., vol.84, pp.818-831, 2019 